\title{
In vitro antifungal activity of Pongamia pinnata against collar rot pathogen (Sclerotium rolfsii) of Chickpea
}

\author{
Abida Akram, Iram Shaheen, Shaista Akhund, Brian Gagosh \\ Nayyar and Wajiha Seerat* \\ Department of Botany, Pir Mehr Ali Shah Arid Agriculture University, Rawalpindi, Pakistan \\ *Corresponding author's email: wajihaseerat@gmail.com \\ Citation \\ Abida Akram, Iram Shaheen, Shaista Akhund, Brian Gagosh Nayyar and Wajiha Seerat. In vitro \\ antifungal activity of Pongamia pinnata against collar rot pathogen (Sclerotium rolfsii) of chickpea.Pure \\ and Applied Biology. Vol. 5, Issue 3, pp. http://dx.doi.org/10.19045/bspab.2016.50066
}

\begin{tabular}{llll}
\hline \hline Received: 04/11/2015 & Revised: 13/05/2016 & Accepted: 25/05/2016 & Online First: 17/06/2016 \\
\hline \hline
\end{tabular}

\section{Abstract}

Present study was conducted to evaluate the antifungal activity of leaves and seed oil of Pongame (Pongamia pinnata) with the help of Poisoned Food Technique against Sclerotium rolfsii. Autoclaved and non autoclaved treatments were observed at all three stages of life cycle of the $S$. rolfsii. Highest inhibition by pongame products was showed at $30 \%$ concentration. Pongame leaves diffusate was more effective against all three stages of Sclerotium rolfsii than seed oil and leaf decoction. Heat treatment reduced the effect of seeds oil, leaf decoction and diffusate. Present study indicated that Pongamia pinnata exhibits promising antifungal potential and further studies on isolation and characterization of active (antifungal) compounds are needed. These compounds can be used for ecofriendly management of fungal pathogens.

Key words: Antifungal; chickpea; collar rot; Pongamia pinnata; Sclerotium rolfsii

Introduction

Chickpea (Cicer arietinum L.) is an important grain legume crop sown under rainfed conditions in Pakistan [1]. It is not only a major source of dietary protein for human consumption but also plays an important part in the management of soil fertility because root nodules having the ability to fix nitrogen [2]. Total cultivated area of chickpea is 12.0 million hectares globally with MT production rate of 10.9 million and an average yield of 913 $\mathrm{kg} \mathrm{ha}^{-1}$ [3]. Its total production quantity in Pakistan was 496,000 tones with average yield of $470.7 \mathrm{~kg} \mathrm{ha}^{-1}$ and total cultivated area is $1,053,800$ hectares [4]. Among various factors causative towards its low production, natural constraints, mainly diseases are the most significant. Due to these conditions, Pakistan has extremely low yield as compared to potential yield of commercial chickpea cultivars [5]. Collar rot is one of the several fungal diseases caused by Sclerotium rolfsii Sacc. affecting this crop and is reported almost all over the world where ever chickpea is grown [6]. S. rolfsii is a destructive soil-borne plant pathogenic 
fungus with a broad range of host, has productive growth and ability to produce persistent Sclerotia causative to losses of high degree at economic level [7]. For the soil borne pathogens, use of fungicides is not practical due to exorbitant cost and environmental hazards involved [8]. For the identification of alternative methods for plant protection, a serious search is needed which are less reliant on chemicals and are more environmentally friendly [9].

Numerous reports are based on the potential use of biocontrol agents as alternatives for agrochemicals $[10,11]$. Plant extracts $[12,13]$ and essential oils [14] show antifungal activity against a wide range of fungi. In the traditional system of medicines, such as Ayurveda and Unani, the plant Pongamia pinnata is used for anti-nonciceptive, antidiarrhoeal, anti-inflammatory, antilipidperoxidative, anti-ulcer, antihyperglycamic, anti-hyperammonic and antioxidant, anti-plasmodial activity [15]. More recently, as a source of biomedicines, the effectiveness of $P$. pinnata has been reported [16] specifically as therapeutic and antimicrobial agents. Using the biological sources to get better economy is an old tradition of human history. Biological control agents provided chickpea protection against collar rot and caused plant growth promotion of chickpea. Hence, the attempt was made to evaluate the effect of different Pongame products as a biocontrol of $S$. rolfsii, responsible for the Collar rot disease of Chickpea.

\section{Materials and methods}

Test microorganism

Isolates of Sclerotium rolfsii used in this study were obtained from mycological collection of Department of Botany, PMAS-Arid Agriculture University, Rawalpindi. The isolates were refreshed and maintained on Potato Dextrose Agar (PDA) medium amended with antibiotic (streptomycin $100 \mu \mathrm{g} / \mathrm{ml}$ ) and observed daily for the emergence of colonies. Sub culturing was done by single spore inoculation method for obtaining pure culture. Pure cultures were kept at $4{ }^{\circ} \mathrm{C}$ and sub-cultured once in a month.

\section{Collection, preparation and preservation of Pongamia pinnata products}

Pongame (Pongamia pinnata) seed oil was obtained from Biodiesel Laboratory of Quaid-i-Azam University Islamabad and stored at $4 \pm 1{ }^{\circ} \mathrm{C}$ in refrigerator. Leaves of Pongame were collected from main campus of PMAS-Arid Agriculture University, Rawalpindi, washed with tap water and air dried for one day. Then leaves were packed into envelop and kept in oven at $60{ }^{\circ} \mathrm{C}$ temperature for 3 days until all the moisture vanished and samples were completely dried.

\section{Preparation of pongame leaf extract}

Dried leaves were ground into fine powder in grinder and $100 \mathrm{~g}$ powder was soaked in $500 \mathrm{ml}$ of distilled water. The mixture was refluxed followed by agitation at $200 \mathrm{rpm}$ for 1 hour on mechanical shaker. The extract was filtered through double layer of muslin cloth and the solution was placed immediately in refrigerator for subsequent evaluation of antifungal activity.

\section{Preparation of Pongame leaf decoction}

For the preparation of Pongame leaf decoction, $100 \mathrm{~g}$ of the shade dried leaves were boiled in $100 \mathrm{ml}$ double distilled water till the volume reduced to $25 \mathrm{ml}$ as described in Ayurvedic text [17]. The decoction was centrifuged and then filtration process done through a $0.22 \mu \mathrm{m}$ pore size membrane before use. For each experiment, 5\%, 10\%, 20\% 
and $30 \%(\mathrm{v} / \mathrm{v})$ concentrations of the decoction were used in appropriate medium.

\section{Evaluation of Pongame products}

The culture medium (PDA) of Sclerotium rolfsii was amended with Pongame products at varying concentrations $(5,10,20$ and $30 \mathrm{ml} / \mathrm{L})$ and poured into Petri dishes. PDA media added only with water served as control. Each Petri dish was inoculated with $5 \mathrm{~mm}$ plug of actively growing culture of Sclerotium rolfsii. The inoculated plates were incubated at $25 \pm 2{ }^{\circ} \mathrm{C}$. Radial mycelial growth was measured on 6th day. To know the effect of heat on Pongame products, comparative studies were done by using different Pongame products with and without autoclaving $\left(121^{\circ} \mathrm{C}\right.$ at $\left.15 \mathrm{psi}\right)$. Experiment was performed in triplicates. Determination of antifungal activity against mycelial growth and sclerotial production of $S$. Rolfsii

For the measurement of radial mycelia growth, two perpendicular lines joining the margin of mycelium to the plug were drawn. Growth measured along these lines was averaged to get single growth value. On the basis of these growth values, inhibition in the mycelial growth (MGI) in comparison with control was calculated by using the following formula;

MGI $=\frac{\text { Mycelial growth in control }- \text { Mycelial growth in treatment }}{\text { Mycelial growth in control }} \times 100$

For the assessment of Sclerotial production in the Sclerotia harvested from replicates of each treatment after 15 days, sclerotial weight of each treatment was averaged to get mean weight of Sclerotia per plate. Inhibition of Sclerotial production (SPI) was calculated by following formula; SPI $=\frac{\text { Sclerotial production in control }- \text { Sclerotial production in treatment }}{\text { Sclerotial production in control }} \times 100$

Bioassay to evaluate antifungal activity against Sclerotial germination
In case of sclerotial germination, all Sclerotia were harvested from 15 days old cultures of Sclerotium rolfsii with the help of brush. Surface sterilized Sclerotia were placed on media mentioned with pongame products at the rate of 6 Sclerotia per plate. Three replicates were made for each treatment. Inhibition in Sclerotial germination (SGI) was calculated in comparison with control by using following formula; SGI $=\underline{\text { Sclerotial germination in control-Sclerotial germination in treatment }} \times 100$ Means for mycelial growth inhibition, sporangial production and sclerotial germination were calculated along with standard errors.

\section{Statistical analysis}

Each treatment was performed thrice and the results were expressed as their mean \pm standard deviation. Analysis of variance (ANOVA) was done for finding differences in the mean values amongst the treatment groups. Further, between the means of the test and the control observations, significance of the difference was established. Statistical analyses were performed using the software Prism 4.0 (GraphPad, Inc.). $\mathrm{P} \leq 0.05$ was considered to be statistically significant.

\section{Results and discussion}

Results on in vitro inhibition of $S$. rolfsii with Pongamia pinnata products are presented in Fig. (1-9). Inhibition in mycelial growth, sclerotial production and germination was studied at 5, 10, 20 and $30 \% \mathrm{v} / \mathrm{v}$ concentration of seeds oil and leaves of Pongamia pinnata. The results were analyzed statistically at $P=0.05$. Significant difference was observed in efficacy of Pongamia pinnata seeds oil and leaves in autoclaved and non-autoclaved treatments at all stages of life cycle of the $S$. rolfsii. On unamended control, no inhibition of $S$. rolfsii was observed. The effect of seeds oil and leaves 
powder and diffusate was reduced by heat treatment.

Effect of Pongamia pinnata seeds oil on mycelial growth, sclerotial production and germination

Increase in inhibition of mycelial growth was observed in Pongamia pinnata seeds oil without autoclaving as compared with autoclaving (Fig. 1). There was $12 \%$ increase in inhibition with autoclaving and $16 \%$ without autoclaving. The effect of Pongamia pinnata seeds oil on sclerotial production was effective and it was increased with increase in concentration. There was less inhibition $(4 \%)$ at $5 \%$ concentration and doubled at $10 \%$ concentration. Similarly slight increase was observed at $30 \%$ concentration (Fig. 2). There was less inhibition of sclerotial production after with autoclaving (heating effect). With increase in concentration (20-30\%), efficacy of Pongamia pinnata leaf diffusate was almost same. Sclerotial germination against seeds oil of Pongamia pinnata was different with and without autoclaving (Fig. 3). 14\% inhibition of sclerotial germination was observed after autoclaving while 16\% inhibition without autoclaving at 20 and $30 \%$ concentration.

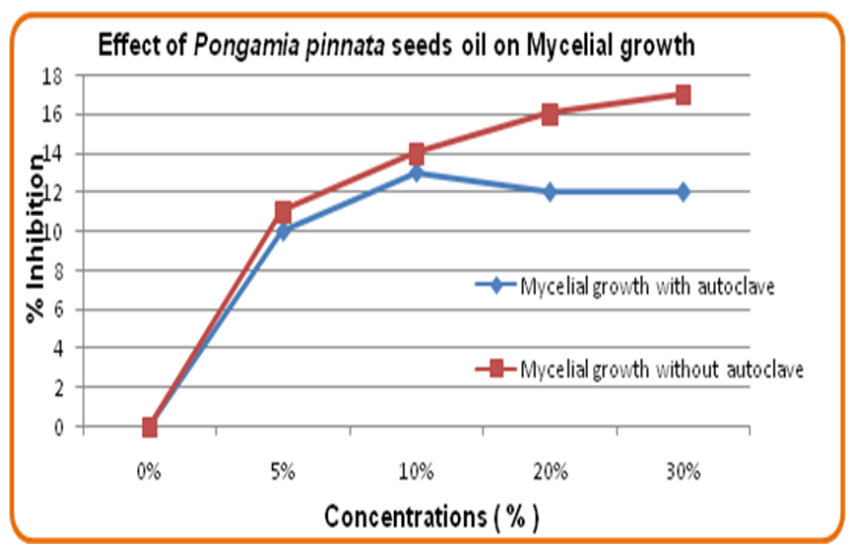

Figure 1. Efficacy of $\boldsymbol{P}$. pinnata seeds oil on mycelia growth with and without autoclave

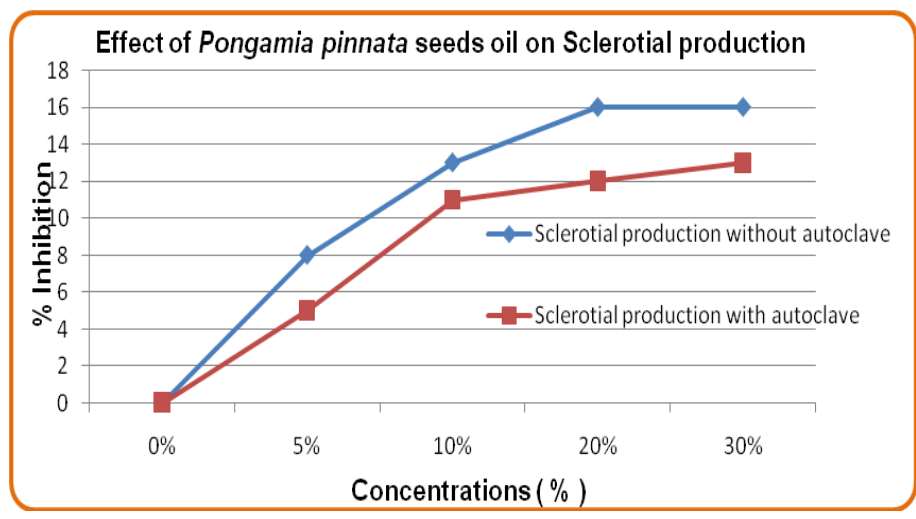

Figure 2. Efficacy of $\boldsymbol{P}$. pinnata seeds oil on sclerotial production with and without autoclave 


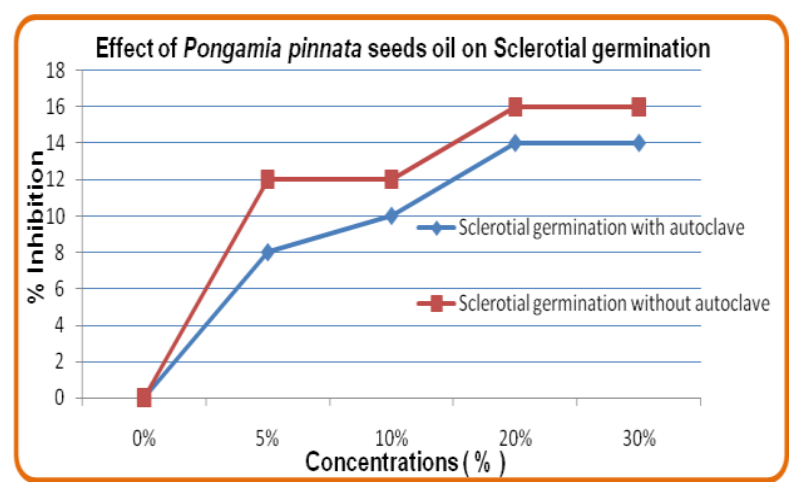

Figure 3. Efficacy of $P$. pinnata seeds oil on sclerotial germination with and without autoclave

\section{Effect of Pongamia pinnata leaf diffusate on mycelial growth,} sclerotial production and germination Pongame leaves diffusate was more effective in inhibiting the mycelial growth and sclerotial germination than seeds oil. The results showed that the effect of heating was not significant and unamended control was without inhibition (Fig. 4). There is no difference observed in efficacy of leaf diffusate with and without autoclaving. Highest percentage of inhibition was observed during sclerotial production in
Pongamia pinnata leaves diffusate. It has shown same effect with and without autoclaving (Fig. 5). Highest inhibition was observed at $30 \%$ concentration. Efficacy was increased with increase in concentration of leaf diffusate. The effect of Pongamia pinnata leaf diffusate on sclerotial germination was observed highest at 20 and $30 \%$ concentration. It was slightly increased with concentration and effect of heat while without heat was considerably low (Fig. 6).

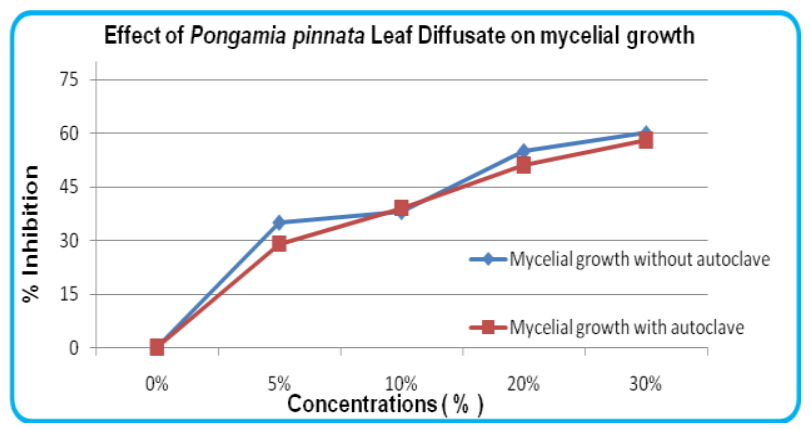

Figure 4. Efficacy of $P$. pinnata leaf diffusate on mycelia growth with and without autoclave

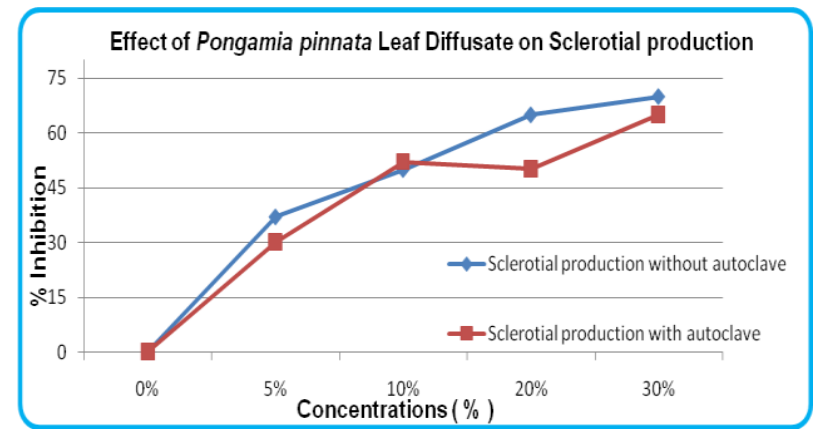

Figure 5. Efficacy of $P$. pinnata leaf diffusate on Sclerotial production with and without autoclave 


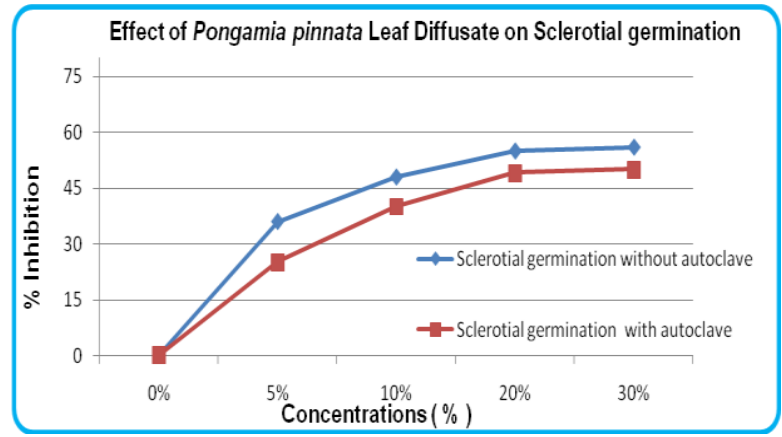

Figure 6. Efficacy of $\boldsymbol{P}$. pinnata leaf diffusate on sclerotial germination with and without autoclave

Effect of Pongamia pinnata leaf decoction on mycelial growth, sclerotial production and germination Highest inhibition rate on mycelial growth was observed at concentration of $30 \%$ leaf decoction. There was no difference observed in efficacy of leaf decoction with and without autoclaving (Fig. 7). Leaf decoction has shown same inhibition effect on sclerotial production as on mycelial growth. There is no significant difference in efficacy of leaf decoction with and without autoclaving. Highest inhibition rate was observed by leaf diffusate in sclerotial production (5\% to 60\%) (Fig. 8). Lowest rate of inhibition on sclerotial germination was observed by leaf decoction. The rate of inhibition of sclerotial germination was same for all the concentrations from 5\%, $10 \%, 20 \%$ to $30 \%$ (Fig. 9).

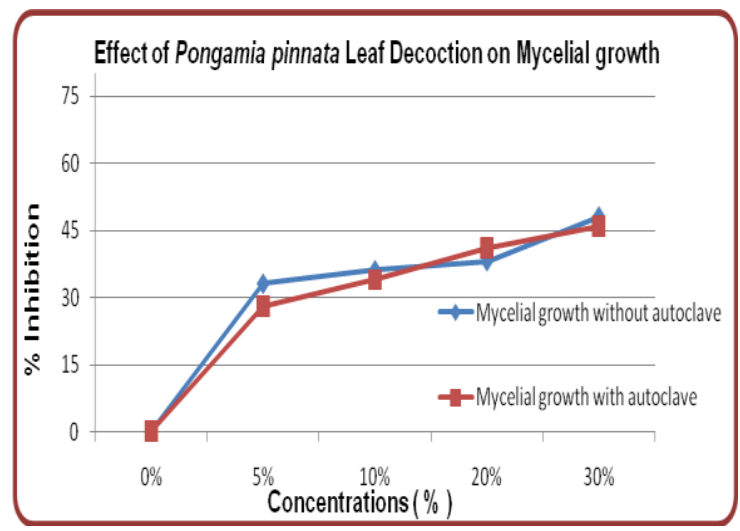

Figure 7. Efficacy of $\boldsymbol{P}$. pinnata leaf decoction on mycelia growth with and without autoclave

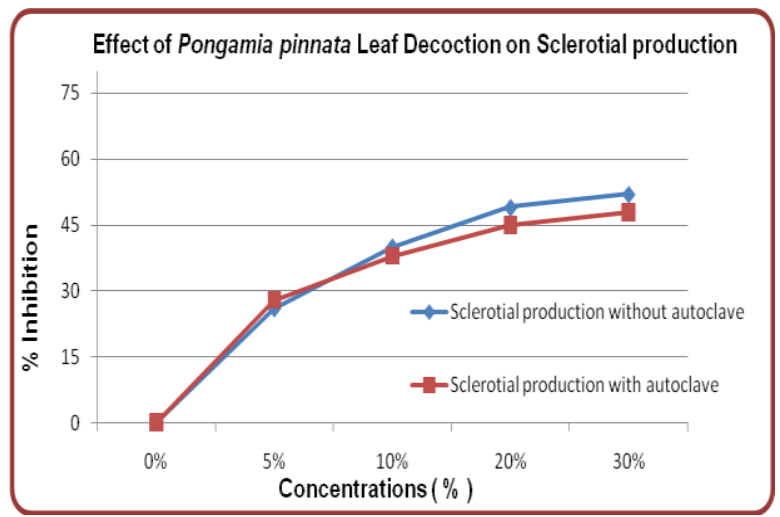

Figure 8. Efficacy of $P$. pinnata leaf decoction on sclerotial production with and without autoclave 


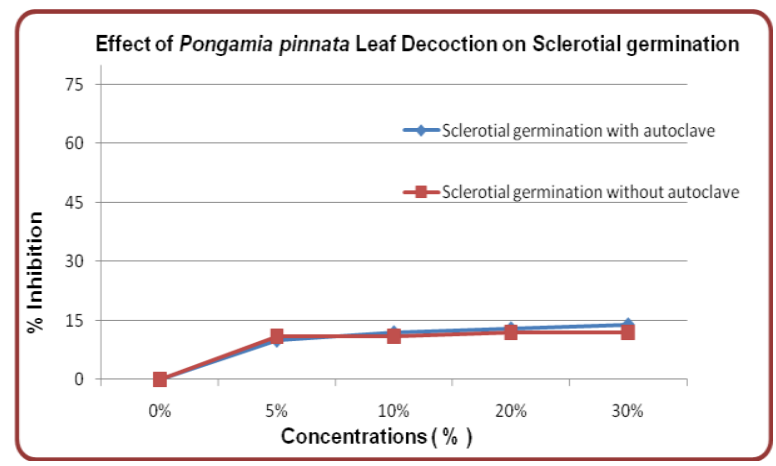

Figure 9. Efficacy of $P$. pinnata leaf decoction on sclerotial germination with and without autoclave

\section{Discussion}

All the concentrations of the Pongame products inhibited the pathogen in varying degrees. Maximum inhibition was observed at $30 \%$ concentration of leaf diffusate of $P$. pinnata when used without autoclaving (Fig. 4-6) while less inhibition was observed with Pongame leaf decoction (Fig.7-9). This seems to be due to active ingredients present in large concentration of leaf diffusate. Thus effectiveness of leaf based products of Pongame was more than its seeds based products. Leaves have high efficacy and antifungal activity because of presence of flavonoids and thermostatic nature [18]. Flavonoids were found to have effective antimicrobial and antifungal activities. Flavonoids are known to inhibit cytoplasmic membrane function, stop nucleic acid synthesis and also slow down energy metabolism in microorganisms [19]. Wagh et al. [20] evaluated antibacterial and antifungal activity of Pongamia pinnata oil with different concentrations against Aspergillus fumigatus, A. niger, Pseudomonas aeruginosa and Staphylococcus aureus by employing dry-weight method and Minimum Inhibitory Concentration (MIC) determination. Presence of fatty acid has shown by performing chemical analysis of $P$. pinnata oil. They proposed the use of fatty oil of
Pongamia pinnata for developing plant derived antimicrobial drugs. Heating effects also indicated that leaves have their ingredients not always constant after autoclaving. Ingredients affected by heat shown that there are some agents present which are sensitive to heat and thus alter their composition with effect of heat. These agents may be proteins and carbohydrates. Pongame seeds oil was less effective as compared to leaves. Seeds oil cannot retain their ingredients constant after autoclaving. When the extract was used without autoclaving the difference in inhibition among the concentrations was nonsignificant except $20 \% \mathrm{v} / \mathrm{v}$ where significant increase in inhibition was observed in case of mycelial growth, inhibition in sclerotial production and germination.

\section{Conclusion}

Present study indicated that effect of Pongamia pinnata products at certain concentrations have antifungal activities that are fungistatic rather than fungitoxic in inhibiting the mycelial growth, sclerotial production and germination of $S$. rolfsii. This study gives a new idea and method of managing disease of chickpea through biological control. The Pongame plant shows antifungal activity which will help in future for isolating and purifying active compounds in biochemical perspective. Suitable selection of 
concentrations, formulation and method of application could also help in further exploration of Pongamia pinnata plant related research.

\section{Authors' contributions}

Conceived and designed the experiments: A Akram, Performed the experiments: I Shaheen, Analyzed the data: $S$ Akhund, Contributed reagents/materials/analysis tools: BG Nayyar, Wrote the paper: W Seerat.

\section{References}

1. Hules JH (1991). Nature, composition and utilization of grain legumes. In: Uses of tropical legumes. Proceedings of a Consultants' meeting, 27-30 March 1989. ICRISAT Patancheru, AP 502 324, India. pp. 11-27

2. Hossain S, Ford R, McNeil D, Pittock C \& Panozzo J (2010). Inheritance of seed size in chickpea (Cicer arietinum L.) and identification of QTL based on 100seed weight and seed size index. $J$ Crop Sci 4: 126-135.

3. Sheehy T \& Sharma S (2012). The nutrition transition in the Republic of Ireland: trends in energy and nutrient supply using Food and Agriculture Organization food balance sheets. Brit J Nutr 106: 1078-1089.

4. Newman S, Slingenbergh J, Kaeslin E, Reantaso M, Subasinghe R \& Lubroth J (2012). Realising one health: How the food and agriculture organization of the United Nations envisions success source. Eco Health 7: 110-111.

5. Ilyas MB, Chaudhry MA, Javed N, Ghazanfar MU \& Khan MA (2007). Sources of resistance in chickpea germplasm against Ascochyta blight. Pak J Bot 39(5): 1843-1847.

6. Nene YL, Sheila VK \& Sharma SB (1984). A world list of chickpea (Cicer arietinum L.) and pigeonpea (Cajnus cajan (L.) Millsp.) pathogens. ICRISAT Pulses Pathology Progress Report 32: 19.

7. Mahen VK, Mayee CD, Brenneman TB \& McDonlad D (1995). Stem and pod rots of groundnut. Information Bulletin No. 44. ICRISAT, Patancheru 502324 AP, India. pp 23.

8. Harman G (1991). Seed treatments for biological control of plant disease. Crop Prot 10: 166-171.

9. Nair JR, Singh G \& Sekar V (2002). Isolation and characterization of a novel Bacillus strain from coffee phyllosphere showing antifungal activity. J of Appl Microbiol 93: 772780.

10. Shimizu M, Nakagawa Y, Sato Y, Furumai T, Igaroshi Y, Onaka H, Yoshida R \& Kunoh H (2000). Studies on endophytic actinomycetes I Streptomyces sp. isolated from Rododendron and its antifungal activity. $J$ Gen Plant Pathol 66: 360-366

11. Yang L, Xie J, Jiang D, Fu Y, Li G \& Lin F (2007). Antifungal substances produced by Penicillium oxalicum strain PY-1- potential antibiotics against plant pathogenic fungi. World $J$ Microbiol Biotechnol 24: 909-915

12. Davidson PM \& Parish ME (1989). Methods for testing the efficacy of food antimicrobials. Food Technol 43: 148-155.

13. Grange M \& Ahmed S (1988). Handbook of Plants with Pest Control Properties. John Wiley \& Sons, New York.

14. Singh AK, Dickshit A, Sharma ML \& Dixit SN (1980). Fungitoxic activity of some essential oils. Econ Bot 34: 186-190.

15. Chopade VV, Tankar AN, Pande VV, Tekade AR, Gowekar NM, Bhandari SR \& Khandake SN (2008). Pongamia pinnata: Phytochemical constituents, 
traditional uses and pharmacological properties: A review. Int J Green Pharm 2: 72-5.

16. Brijesh S, Daswani PG \& Tetali P (2006). Studies on Pongamia pinnata (L.) Pierre leaves: understanding the mechanism(s) of action in infectious diarrhea Journal of Zhejiang University Science B 7(8): 665-674.

17. Thakkur CG (1976). The Art and Science of Pharmacy. In: Introduction to Ayurveda: Basic Indian Medicine, 2nd Ed. Gulakunverba Ayurvedic Society, Jamnagar (India). P. 107-111.

18. Sadri NL, Vibhavari Y, Deshtande $\mathrm{KN}$, Mendulkar D \& Nandal H
(1983). Male antifertility activity of Azadirachta indica in different species. In: Natural Pesticides from Neem tree (Azadirachta indica A. Juss) and other tropical plants. Deutsche Gesellschaft for Technische Zusammenarbeit (GTZ), Eschborn, Germany. pp. 473-482.

19. Tim TP \& Lamb AJ (2005). Antimicrobial activity of flavonoids. Internat $J$ of antimicrobial agents 26: 343-356.

20. Wagh P, Rai M, Deshmukh SK \& Durate MCT (2007). Bio-activity of oils of Trigonella foenum- graecum and Pongamia pinnata. African J Biotech 6(13): 1592-1596. 